\title{
Educação para a Sustentabilidade: Implicações para o Currículo Escolar e para a Formação de Professores
}

\author{
Ana Maria Freire \\ Centro de Investigação em Educação \\ Universidade de Lisboa, Portugal
}

Resumo: Na sociedade actual, começamos a estar cada vez mais conscientes da necessidade de construir um futuro sustentável. A educação desempenha, por isso, um papel fundamental, sentindo-se a necessidade de um maior investimento a nível da formação de professores e da investigação. Nesta comunicação, discute-se o significado de sustentabilidade e de desenvolvimento sustentável, as orientações curriculares para o ensino da temática, a formação de professores e a investigação educacional que melhor se coaduna com esta dimensão. Com efeito, a educação para a sustentabilidade implica perspectivar uma nova orientação para a prática lectiva, enfatizando situações de aprendizagem activas, experienciais, colaborativas e dirigidas para a resolução de problemas a nível local, regional e global. Isto requer um novo modo de pensar o ensino e a aprendizagem que, certamente, influenciará a formação de professores.

Palavras-chave: Sustentabilidade. Desenvolvimento Sustentável. Educação para a Sustentabilidade. Formação de Professores.

Abstract: Society needs that we think about a sustainable future. So, education for sustainability must be a goal with investment concerning teacher education. This paper discusses sustainability and sustainable development, guidelines for teaching this thematic, teacher education and educational research. Education for sustainability implies a new orientation or teaching with more pupil-centred learning situations and with problem-based learning at local, regional and global level. 
Keywords: Sustainability. Sustainable Development. Education for Sustainability. Teacher Education.

Neste artigo, que serve de suporte para o Grupo de Discussão e Pesquisa (GDP), pretende-se colocar questões que podem dirigir a discussão sobre três temas de interesse actual para a educação para a sustentabilidade. Primeiro, apresenta-se o significado de sustentabilidade e de desenvolvimento sustentável. Em segundo lugar, reflecte-se sobre as finalidades e estratégias de ensino subjacentes à educação para a sustentabilidade e apresentam-se as orientações curriculares para o ensino da temática que foram definidas no meu país. Em terceiro lugar, discute-se a formação de professores e a investigação educacional que melhor se coadunam com esta dimensão. Com efeito, a educação para a sustentabilidade implica perspectivar uma nova orientação para a prática lectiva, enfatizando situações de aprendizagem activas, experienciais, colaborativas e dirigidas para a resolução de problemas a nível local, regional e global. Isto requer um novo modo de pensar o ensino e a aprendizagem que, certamente, influenciará a formação de professores. Programas de formação de professores baseados no paradigma da reflexão em acção enfatizam um modelo onde os professores são levados a pensar sobre problemas da sua prática, a prever uma solução, a implementá-la, a reflectir sobre acção e a introduzir mudanças, envolvendo-se assim no ciclo de acção - reflexão - acção repensadas (SAGOR, 2005). Esta pode ser uma estratégia que promove a aprendizagem ao longo da vida e que está em sintonia com a educação para a sustentabilidade.

\section{Significado de Sustentabilidade e de Desenvolvimento Sustentável}

$\mathrm{Na}$ sociedade actual, começamos a estar cada vez mais conscientes da necessidade de construir um futuro sustentável. Discute-se hoje o significado de sustentabilidade e as características que lhe estão subjacentes, não havendo entre os peritos um consenso acerca do seu significado, embora se reconheça $O$ 
imperativo de práticas suportadas por uma acção mais informada e preocupada com o equilíbrio entre os sistemas ambientais, económicos e sociais, a nível planetário. A Conferência do Rio de Janeiro de 1992 veio chamar a atenção para a problemática da educação de modo a traduzir a perspectiva de sustentabilidade e de relacionar o nosso bem-estar económico com as tradições culturais e o respeito pela Terra e seus recursos. Contudo, para atingir estas finalidades, algo deve mudar, quer a nível curricular, quer a nível das práticas, tornando-se, para tal, necessário uma transformação do nosso modo de pensar e de agir no quotidiano escolar. A educação desempenha, por isso, um papel fundamental, sentindose a necessidade de um maior investimento a nível da formação de professores e da investigação. Pretende-se definir sustentabilidade e desenvolvimento sustentável, mas as dificuldades surgem porque estes conceitos constituem tanto um modo de pensar acerca das coisas como conteúdo do nosso pensamento. Zaccai (2002) considera que as expressões que definem desenvolvimento sustentável (DS) são relativamente consensuais, mas não fornecem os critérios necessários para realizar uma avaliação. Estabelecem condições para o futuro, a necessidade de se considerar o ambiente natural e de integrar de um modo equilibrado as dimensões económicas, sociais e ambientais. De acordo com Wheeler (2000), três sistemas são tidos em conta quando descrevemos desenvolvimento sustentável: económico, social e ambiental, cada um integrando os seus subsistemas e, por isso, podemos falar sobre sistema de ideias inter-relacionadas. Porém, cada um de nós pode observar, interpretar e comunicar o seu ponto de vista de modo diferente dependendo dos seus conhecimentos, interesses e valores. A emergência desta diversidade de posições conduz a múltiplas perspectivas sobre desenvolvimento global e exige que se pense holisticamente.

Gostaria de começar os trabalhos neste GDP por uma actividade prática, "Esgotar ou Sustentar", adaptada de Rizzi (2002) (Apêndice 1), para discutir o significado de sustentabilidade e de desenvolvimento sustentável. 


\section{Actividade Prática}

Formar Grupos de 4 elementos. Explicar as regras do jogo. Distribuir o guião 1 (Apêndice 1) e o material necessário.

Tendemos a dividir o conceito de sustentabilidade em três partes, pensando que, com base no conhecimento de cada uma, ambiente, economia e sociedade, poderemos atingir o todo. De acordo com Wheeler (2000), esta estratégia poderá incutir a ideia de que sustentabilidade depende de três campos distintos e não permitir que se adquira uma ideia global. Por isso, o autor sugere que se integre os três campos e se pense em cinco temas transversais que nos permitem adquirir uma ideia mais global:

i. Pensar sobre o futuro;

ii. Criar comunidades sustentáveis;

iii. Cuidar dos recursos naturais;

iv. Projectar economia sustentável;

v. Globalização.

Pensar sobre o futuro. Com efeito, sustentabilidade e desenvolvimento sustentável estão indissociavelmente ligados ao futuro. As escolhas que fazemos hoje para melhorar as condições de vida para nós e para os nossos descendentes afectam o modo de viver futuro. Vou dar um exemplo. Este ano em Portugal, estamos a viver uma grande crise, com falta de água em virtude de não ter chovido durante o Inverno e de a água não ter sido reposta nas nossas barragens. Precisamos de água para o nosso consumo doméstico, para os nossos jardins, para os nossos campos de golfe, para as nossas fábricas, para a nossa agricultura e para a nossa pecuária. Onde vamos buscar a água? Qual é a primeira prioridade? Quem decide? Qual é a legitimidade do decisor? Que papel cabe a cada um dos cidadãos na decisão? Se cada um dos agricultores accionar os furos subterrâneos para retirar a água que temos no presente a fim de responder à crise actual, não estará a hipotecar o futuro? Será que as perspectivas individualistas se podem sobrepor às colectivas? Sustentabilidade requer que se pense no futuro e nas consequências das nossas acções de hoje no bem-estar futuro de 
todos. Requer que o individualismo seja substituído por práticas mais solidárias, implicando, por isso, uma educação para os valores.

Criar comunidades sustentáveis. É importante nos dias de hoje projectar sociedades mais sustentáveis, onde os interesses da comunidade se sobreponham aos interesses individuais. Um bom projecto necessita acautelar as questões ambientais, as questões sociais e não descuidar das questões económicas. Contudo, esta prática parece difícil de implementar. Há sempre uma diversidade de interesses que devem ser acautelados. Vou dar um exemplo do meu país. Há cerca de 10 anos, a barragem de Foz Côa foi mandada suspender pelo poder político por se terem encontrado figuras rupestres que evidenciavam que Portugal tinha sido habitado por povos muito antigos. Vieram especialistas de toda a Europa e confirmaram aquilo que os nossos arqueólogos tinham concluído. Terá sido a melhor decisão? Como proteger as figuras rupestres e ajudar a desenvolver a população local? O estado gastou dinheiro, as obras foram paradas, não houve retenção de água ou a construção da central hidroeléctrica que permitia obter energia eléctrica e as figuras não foram exploradas. O que fazer para tornar esta cidade do interior sustentável? Desenvolver o turismo para permitir observar as figuras e compensar a falta de recursos, criando outros pólos de trabalho? Quem toma a iniciativa? As pessoas da cidade? $\mathrm{O}$ poder político? Quem investe? Como promover um turismo sustentável?

Cuidar dos recursos naturais. Esta ideia constitui o ponto fundamental de uma sociedade sustentável. Se nós gastarmos hoje tudo, não estaremos a deixar para a geração futura. Quero dar outro exemplo do meu país. No tempo dos romanos, existia uma pequena cidade nas margens do rio Guadiana que faz fronteira com a Espanha, na Andaluzia, que se chama Mértola. Nessa região, abundava o ouro e a prata e cobre, em céu aberto. As galeras romanas subiam o rio até Mértola e carregaram o precioso metal para Roma (nos séculos II e III DC). Esta cidade foi depois cidade dos mouros e desde o século XIII (1243) integra o território português. A nossa história conta as riquezas desta cidade que dista $100 \mathrm{~km}$ do mar e que está para além das serranias. É interessante do ponto de vista arqueológico, pólo de encontro de culturas, mas as riquezas do passado nunca puderam ser repostas. Todavia, hoje 
o turismo permite-nos reconstruir a riqueza da cidade e encontrar postos de trabalho que possibilitam uma vida sustentável para todos. Esgotamos hoje os nossos recursos a um ritmo superior à sua reposição, correndo o risco de não os legar para as gerações vindouras. Será legítima esta nossa actuação? Que políticas devem ser preconizadas? Sustentabilidade e desenvolvimento sustentável requerem que se equacione este problema tão visível nos dias de hoje quando não acautelamos a velocidade de reposição dos recursos. O que legamos? Quem tem a responsabilidade? Como a exercer? Como influenciar as políticas? Qual o papel da Educação?

Desenvolver Economia Sustentável. O desenvolvimento de uma economia sustentável constitui um desafio nos dias de hoje. Para além de considerar somente o capital económico, que inclui a troca de bens, há que atender aos capitais intelectual, natural, social e espiritual. É, pois, através da consideração destas vertentes e de um atendimento a todos eles que a economia se desenvolve numa maneira sustentável. A economia sustentável requer que os patrões não retirem tudo para si mas que atendam aos recursos naturais e intelectuais, à qualidade de vida dos seus trabalhadores, do ponto de vista social e espiritual. Na Europa, a Estratégia de Lisboa em 1999 juntou o pilar ambiental ao social e ao económico. Como coordenar? Quem? A que nível? Qual o peso da educação?

Globalização. Nos nossos dias, interessa saber como as acções que nós desenvolvemos na nossa pequena comunidade afectam localmente e globalmente. Globalização constitui um campo de acção que começa a existir ao nosso redor, que influencia a nossa maneira de viver e que nos faz sentir indefesos e sem poder. É, por isso, necessário actuar a nível do sistema educativo para ajudar os alunos a compreender que a nossa actuação local tem influência global, a reconhecer o impacto da globalização nas nossas vidas e a resistir aos seus impactos. Os efeitos da globalização estão a fazer-se sentir no meu país com a deslocalização das empresas para outras regiões e o desemprego a subir entre aqueles cujas competências se situam a nível do fazer. É, por isso, necessário investir a nível do capital intelectual e criar a necessidade do empreendedorismo. De acordo com Wheeler (2000), isto requer uma profunda compreensão dos sistemas económicos, sociais e ambientais, o reconhecimento da inter- 
relação entre estes sistemas num mundo sustentável e o respeito pela diversidade de pontos de vista e de interpretações numa sociedade complexa, onde se cruzam indivíduos com valores religiosos, raciais, éticos e intergeracionais distintos. É uma tarefa ciclópica para os educadores deste início do século XXI.

\section{Educação para a Sustentabilidade}

Nos dias de hoje, não podemos pensar numa comunidade sustentável se não se actuar a nível da educação e, por isso, tal atitude constitui um imperativo. A UNESCO, a ONU e todos os organismos mundiais estão a apelar nesse sentido. Reorientar a educação em direcção ao desenvolvimento sustentável requer um novo modo de pensar. O capítulo 36 da Agenda 21 (UNESCO, 2002) apela a que se considere a educação como um processo através do qual todos os seres humanos e sociedades podem alcançar o seu potencial mais elevado. Educação para o desenvolvimento sustentável está a emergir como um conceito dinâmico que engloba uma nova perspectiva de educação que procura integrar todas as pessoas de modo a levar a assumir a responsabilidade de criar um futuro sustentável. Torna-se, por isso, necessário educar para a sustentabilidade e a Ciência constitui o veículo essencial. Na realidade, a ciência para todos e o movimento da literacia científica começaram, a partir dos anos 80, a emergir como um imperativo em diferentes países (DEBOER, 1991; FENSHAM, 2000). Ainda que todos concordem sobre a necessidade de se ensinar ciência a todos, independentemente da nacionalidade, do género, das origens culturais e das circunstâncias socioeconómicas, existem diversas orientações e dependem dos aspectos que se valorizam. DeBoer (2000) considera que o mais importante é encontrar um equilíbrio entre as várias dimensões da ciência, substantiva, sintáctica, axiológica, histórica, sociológica e política. Assim, um ensino de ciências para todos que englobe as diferentes dimensões da ciência e que considere a necessidade da educação para a sustentabilidade constitui uma recomendação da UNESCO (2002).

Em Portugal, a reorganização curricular que ocorreu nos anos 2001 e 2002 proporcionou a junção das Ciências Naturais e 
das Ciências Físico-Químicas, que se constituíram nas Ciências Físicas e Naturais e que podem ser leccionadas colaborativamente pelos professores das duas áreas disciplinares. Assim, surgiram as Orientações Curriculares (OCs) para os alunos do $3^{\circ}$ ciclo $\left(7^{\circ}, 8^{\circ}\right.$ e $9^{\circ}$ anos) da escolaridade obrigatória (GALVÃO et al, 2002). As OCs integram quatro temáticas, Terra no Espaço, Terra em Transformação, Sustentabilidade na Terra e Viver Melhor na Terra e explicitam as competências a desenvolver pelos alunos através das experiências de aprendizagem que são sugeridas. Estas pressupõem um papel mais activo do aluno na sala de aula e um outro modo de ensinar exigindo que o professor actue como facilitador das aprendizagens e não somente como transmissor de conhecimentos a um conjunto de alunos desejosos de o ouvir. Todavia, a investigação tem vindo a mostrar a dificuldade em implementar um currículo colaborativamente (SÍTIMA, 2005) e de os professores reconhecerem aspectos inovadores das OCs (VIANA \& FREIRE, a aguardar publicação). Os professores continuam a ler o currículo à luz das suas concepções de ensino e não interpretam os documentos como algo inovador. É, por isso, necessário investir na formação de professores.

A UNESCO (1997) adverte que a nossa cultura inclui um conjunto de sistemas de crenças, valores, atitudes, costumes e instituições que enformam as nossas relações sociais e o modo como percebemos o mundo e a nós mesmos e como interactuamos com as outras pessoas e o resto da natureza. Assim, a crise global que vive a humanidade é resultado do nosso modo de vida e dos nossos valores colectivos e, por isso, pode-se considerar uma crise cultural. Todavia, a cultura desempenha um papel central na noção complexa de sustentabilidade e qualquer que seja a forma que toma no futuro depende das nossas decisões e das nossas acções a nível local. Um exemplo de como uma decisão local afecta globalmente pode ser o NÃO francês no referendo à Constituição Europeia. $\mathrm{Na}$ realidade, um maior reconhecimento de que as decisões e acções humanas a nível local afectam globalmente o ambiente e o nosso modo de vida leva-nos a pensar na necessidade de explicar finalidades de ensino em consonância com a sustentabilidade do planeta e, por isso, uma nova ética global. Este imperativo implica um investimento a nível da formação de professores. 


\section{Formação de Professores}

Nas últimas décadas, houve uma maior consciência por parte dos educadores e investigadores educacionais sobre o papel desempenhado pelas crenças e pelo conhecimento prévio nas aprendizagens proporcionadas por cursos de formação de professores. Esta consciencialização levou à explicitação de diferentes práticas de formação: construtivista, reflexiva e investigativa (RICHARDSON, 1997; CALDERHEAD e GATES, 1993; ZEICHNER e NOFFKE, 2001).

Os defensores da prática construtivista estão empenhados em introduzi-la como teoria de ensino, nos cursos de preparação de professores. Consideram que a construção de significados é a essência do ensino e da aprendizagem e que a formação de professores deverá ter como finalidade criar condições que possibilitem aos professores aprender a ajudar os alunos a construir significados a partir das situações criadas.

Inquirir sobre os significados e as ideias que os alunos têm acerca dos fenómenos físicos e químicos constitui um ponto de partida para a construção de novos significados mais em sintonia com o pensamento científico. Ensinar os professores a conduzir acções instrucionais que visem a mudança conceptual dos seus alunos constitui uma finalidade da formação de professores orientada pelas teorias construtivistas influenciadas pelas disciplinas científicas de ensino (RICHARDSON, 1997).

Aqueles que preconizam a prática reflexiva na formação de professores valorizam a reflexão como processo que pode contribuir para ajudar os professores a aprender a ensinar. Neste caso, a reflexão é entendida como um elemento essencial ao desenvolvimento profissional (CALDERHEAD e GATES, 1993). A prática reflexiva é considerada um bem em si mesmo, numa época em que os professores são tidos por alguns como técnicos ou implementadores do currículo formal, sem atender à complexidade cognitiva subjacente à actividade docente. Importa, por isso, distinguir como as perspectivas construtivista e reflexiva têm sido equacionadas pelos educadores. As perspectivas construtivistas e reflexivas distinguem-se pelo modo diferenciado como se relacionam com a aprendizagem dos conteúdos científicos. 
$\mathrm{Na}$ perspectiva de educar para a sustentabilidade, é importante levar os professores a reflectir sobre as implicações das suas acções nos seus alunos e na sociedade requerendo e emergência de interesses emancipatórios (HABERMAS, 1982). A introdução de práticas investigativas na formação de professores parece estar em sintonia com a necessidade de uma mudança cultural para promover a educação para a sustentabilidade. De acordo com Zeichner e Noffke (2001), o conceito de prática como produção de conhecimento é essencial, pois promove o desenvolvimento individual e vai para além dos contextos privado e local, contribuindo para uma melhoria educacional e social.

A formação de professores num mundo em mudança com a necessidade de preparar os alunos para uma sociedade global exige que se atenda a aspectos distintos. As escolas estão cheias de alunos com uma diversidade de culturas e valores que importa preparar para a sociedade global. Exige uma mudança de paradigma e associar a investigação à prática lectiva. É preciso, por isso, na formação de professores, incluir a perspectiva investigativa de modo que os jovens professores aprendam a investigar as suas práticas, a desenvolver a reflexão na acção e sobre acção nas suas práticas e a comunicar os resultados das suas investigações. Isto requer uma nova postura, mas vai de certo modo dar poder aos professores e responsabilizá-los pelo seu próprio percurso profissional. A decisão curricular do professor encontra-se, neste início do século XXI, na intersecção de três grandes domínios: a relação professor-aluno, com os factores culturais e crenças, o universo da ciência, incluindo a diversidade de conhecimentos e o modo como os conhecimentos podem ser transaccionados, e os constrangimentos definidos em políticas educativas. A formação de professores deverá estar atenta às forças sociais que se fazem sentir na escola e preparar os professores para enfrentar a sociedade global.

\section{Conclusão}

Investigação na prática e comunidades de aprendizagem podem constituir uma estratégia que promova a transformação dos professores. A educação para a sustentabilidade e a necessidade de se pensar de modo distinto requerem o empenhamento de todos 
aqueles que se preocupam com o futuro dos jovens. As mudanças sociais são assaz evidentes e exigem que se tomem medidas a nível do sistema educativo de modo a preparar a geração vindoura a enfrentar os desafios deste novo milénio.

\section{Referências bibliográficas}

CALDERHEAD, J. e Gates, P. Introduction. In: CALDERHEAD, J. e GATES, P. (Eds.). Conceptualizing reflection in teacher development. London: Falmer Press, 1993.

DEBOER, G. A history of ideas in science education: Implications for practice. New York: Teachers College Press, 1991.

Sicentific literacy: Another look at its historical and contemporary meanings and its relationship to science education reform. Journal of Research in Science Teaching, 37(6), 2000, p. 582-601.

FENSHAM, P. J. Providing suitable content in the "science for all" curriculum. In: MILLAR, R., LEACH, J. e OSBORNE, J. (Eds.). Improving science education: The contribution of research. Buckingham, UK: Open University Press, 2000, p. 147-164.

GALVÃO, C. (Coord.); NEVES, A.; FREIRE, A. M.; LOPES, A. M.; SANTOS, M. C.; VILELA, M. C.; OLIVEIRA, M. T. e PEREIRA, M. Ciências Físicas e Naturais. Orientações curriculares para o $3^{\circ}$ ciclo do ensino básico. Lisboa: Ministério da Educação, Departamento da Educação Básica, 2002.

HABERMAS, J. Conocimiento e interés. Madrid: Taurus Ediciones, S. A., 1982 (trabalho original em alemão publicado em 1968).

RICHARDSON, V. Constructivist teaching and the teacher education: Theory and practice. In: RICHARDSON, V. (Ed.). Constructivist teacher education: Building new understandings. London: Falmer Press, 1997.

RIZZI, R. Exercises to introduce the concept of sustainable development. In: MCKEOWN, R. (Ed.). Education for a sustainable development toolkit. 2002.

SAGOR, R. The action research guidebook. Thousand Oaks, CA: Corwin Press, 2005. 
SÍTIMA, M. A. B. Implementar colaborativamente o currículo de Ciências Físicas e Naturais. Dissertação de Mestrado não publicada. Universidade de Lisboa, Faculdade de Ciências, Departamento de Educação, Lisboa, 2005.

UNESCO. Educating for a sustainable future: A transdisciplinarry vision for concerted action. 1997.2 Disponível em: $<$ www.unesco.org/education/tlsf/intro/uncofrm 0 $>$. Acesso em: 13 de junho de 2005 .

Teaching and learning for a sustainable future. 2002. Disponível em: $<$ www.unesco.org/education/tlsf $>$. Acesso em: 13 de junho de 2005.

VIANA, M. P. e FREIRE, A. M. (a aguardar publicação). Perspectivas de professores de Física e Química sobre as orientações Curriculares. Revista de Educação.

WHEELER, K. A. Introduction. In: WHEELER, K. A. e BIJUR, A. P. (Eds.). Education for a sustainable future. A paradigm of hope for the $21^{\text {st }}$ century. New York (NY): Kluwer Academic, 2000.

ZACCAI, E. From conceptions of sustainability to indicators. EASY-ECO EvAlution of SustainnabilitY EuroCOnference, May 23-25, Vienna/Austria, 2002.

ZEICHNER, K. M. e NOFFKE, S. E. Practitioner research. In: RICHARDSON, V. (Ed.). Handbook of research on teaching, $4^{\mathrm{a} e d}$. Washington, D.C.: American Educational Research Association, 2001. 


\section{Apêndice 1}

\section{Actividade Prática 1 - Esgotar ou Sustentar?}

Finalidade - Introduzir o conceito de sustentabilidade Procedimento

1. Dividir o grupo em comunidades de 4 elementos

2. Colocar 16 peças num monte comunitário

3. Ler as regras do jogo

a. O conjunto de peças representa um recurso renovável de grande valor; o recurso é reposto após cada volta

b. Cada membro da comunidade tem que retirar pelo menos uma peça por cada volta, podendo retirar mais se assim o entender

c. Um elemento do grupo regista o número de peças retirado em cada volta e repõe no monte um número de peças igual ao existente

d. Cada grupo joga 2 vezes e faz depois uma pausa para reflectir sobre o que aconteceu na comunidade.

e. Cada grupo joga mais uma volta e partilha os seus resultados com a restante comunidade

Tópicos de Discussão

1. Sobrevivência das comunidades

2. Factores influenciadores da sobrevivência das comunidades

3. Conceito de sustentabilidade

4. Gestão de comunidades sustentáveis

\section{Actividade Prática 2 - Esgotar ou Sustentar?}

Finalidade - Discutir o conceito de sustentabilidade

Procedimento

1. Dividir o grupo em comunidades de 4 elementos

2. Colocar 16 peças brancas num monte comunitário, num saco opaco 
3. Fornecer peças pretas a cada elemento da comunidade

4. Cada comunidade deve escolher, de entre os cenários culturais que se apresentam no quadro seguinte, aquele que considera mais apropriado

\begin{tabular}{|c|l|l|}
\hline Cenários & Peças brancas & Peças pretas \\
\hline 1 & Parcela de terra numa fazenda & Fertilizantes, herbicidas, pesticidas \\
\hline 2 & Terra de pastoreio & Perda de vegetação \\
\hline 3 & Pesca do atum & Diminuição do atum \\
\hline 4 & Viagem de avião & Poluição do ar \\
\hline 5 & Fábrica de calçado & Poluição da água do rio \\
\hline
\end{tabular}

5. Ler as regras do jogo

a. Em cada volta, os participantes devem retirar do saco pelo menos uma peça para poderem sobreviver

b. Cada peça retirada do saco, na primeira e segunda volta ( $1^{a}$ geração), é substituída por uma peça preta

c. $\mathrm{Na}$ terceira e quarta volta ( $2^{\mathrm{a}}$ geração), por cada peça branca retirada, são colocadas três peças pretas

d. Na quinta e sexta volta ( $3^{a}$ geração), por cada peça retirada são colocadas quatro peças pretas no saco

e. Se um participante não retirar do saco uma peça branca, morrerá e não poderá continuar a jogar

f. No fim de cada volta, as peças brancas existentes no saco devem ser contadas e repostas na mesma quantidade

Tópicos de Discussão

1. Sobrevivência das comunidades

2. Factores que influenciaram a sobrevivência das comunidades

3. Influência das acções da $1^{a}$ geração nas acções da $2^{a}$ geração

4. Ruptura do sistema e suas causas

5. Gestão de comunidades sustentáveis 